\title{
EL EFECTO CATÁRTICO Y EL EFECTO TÓNICO DE LA TRAGEDIA. NIETZSCHE FRENTE A ARISTÓTELES
}

The cathartic effect and the tonic effect of tragedy. Nietzsche against Aristotle

\author{
Remedios Ávila Crespo \\ Universidad de Granada
}

RESUMEN: Este trabajo se centra en el estudio de la noción de kátharsis y en el modo como es asumida en las reflexiones respectivas de dos autores que ofrecieron a este concepto un lugar muy relevante en su pensamiento: Aristóteles y Nietzsche. La primera parte, referida a Aristóteles, destaca el papel central de esta noción en la teoría de la tragedia y defiende que es inseparable de la de mimesis. La segunda, centrada en Nietzsche, analiza la polémica de este último con la teoría aristotélica y su defensa de la tragedia como gran estimulante de la vida y como tónico vital.

Palabras clave: Aristóteles - Nietzsche - kátharsis - mimesis - tragedia.

ABSTRACT: This paper is dedicated to the study of the concept of kátharsis and especially to the importance given to this topic in the work of Aristotle and Nietzsche. In the first part of this essay, centred on Aristotle, we will analyse the central role of this notion in the theory of tragedy and we will sustain that it is inseparable from the concept of mimesis. The second part, focused on Nietzsche, considers the polemic raised by this author against the Aristotelian theory and examines Nietzsche's advocacy of tragedy as a great stimulus of life and a vital tonic.

Keywords: Aristoteles - Nietzsche - kátharsis - mimesis - tragedy.

\section{ARISTÓTELES: LA KÁTHARSIS COMO CONOCIMIENTO EMOTIVO}

\subsection{Kátharsis y aprendizaje}

Quisiera comenzar este trabajo destacando tres puntos de partida, algunos de los cuales los he considerado por extenso en trabajos anteriores. En primer lugar, la reflexión de Aristóteles sobre la tragedia responde a la que Platón había sostenido en la República respecto a la poesía y a los poetas ${ }^{1}$ : con las nociones de mimesis y kátharsis Aristóteles contesta a las críticas de su maestro para quien los poetas no dicen la verdad y no contribuyen a la educación de los ciudadanos. A juicio de

1. Véase T. Calvo, «La crítica de Platón a la poesía y al arte», en A. Herrera Guevara (ed.), De animales y hombres, Studia philosophica, Madrid: Biblioteca Nueva, 2007, pp. 223-238. Y también mi trabajo «¿No deberían los poetas volver a la ciudad? Una aproximación filosófica a la relación entre literatura y verdad», en J. F. García Casanova y Á. Vallejo (eds.), Crítica y meditación. Homenaje al profesor Pedro Cerezo Galán, Granada: Universidad de Granada, 2013, pp. 61-84. 
Platón la poesía no cumple, ni por su esencia ni por sus efectos, las condiciones que la harían deseable en la ciudad ideal, mientras que Aristóteles defiende el compromiso de la poesía y del arte en general con la verdad: mimesis y verosimilitud constituyen la esencia de la tragedia y su particular aproximación a la verdad. Pero también por sus efectos debe ser defendida la tragedia: la kátharsis constituye un fin beneficioso y contribuye a la educación y al aprendizaje.

Hay que reconocer, en segundo lugar, una cierta ambigüedad en el modo de entender el término «fin», como ya he señalado en otro lugar a propósito de la definición aristotélica de la tragedia ${ }^{2}$. La tragedia es «imitación (mimesis) de una acción seria (spoudaias) y completa, de cierta dimensión, mediante un lenguaje adornado de formas distintas en cada una de sus partes, con personajes que actúan y no mediante una narración, y que lleva a cabo mediante la compasión (éleos) y el temor (phóbos) la purificación (kátharsis) de pasiones tales» ${ }^{3}$. Y la respuesta a la pregunta sobre el auténtico fin de la tragedia, como señalábamos entonces, depende de lo que se entienda por «fin».

Si por fin entendemos los efectos de la obra de arte, lo que el artista desea provocar en el espectador, Aristóteles no parece albergar duda alguna acerca de tal cosa: el fin de la tragedia es la kátharsis y el medio para conseguir tal fin estriba en la movilización o estimulación del miedo y la compasión, que son las emociones específicas de la tragedia. Si, en cambio, por «fin» entendemos télos, en el sentido de esencia, sustancia o entelequia, la respuesta de Aristóteles es inequívoca: el verdadero fin de la tragedia es la trama, es decir, el mythos, en el sentido de argumento, de configuración, de creación (poíesis) ${ }^{4}$. Pero cabría entender el fin de la tragedia de una tercera forma que en cierto modo incluye tanto el primer sentido (kátharsis) como el segundo (mythos). A eso es a lo que parece apuntar Aristóteles al comienzo de la Poética, cuando señala que el arte es siempre imitación y que todas las artes tienen en común el ser imitaciones ${ }^{5}$. Y es también a lo que apunta el capítulo 4 de esta obra, cuando advierte que el arte es un medio de aprendizaje y que aprender es algo «sumamente grato no solo para los filósofos, sino igualmente para los demás hombres». La tragedia cumple su fin como imitación, es decir, como mimesis y dicha mímesis es conocimiento, aprendizaje, pero, como se intentará mostrar en lo que sigue, en el aprendizaje está directamente implicada la kátharsis.

En tercer lugar, hay que subrayar, aunque sea muy brevemente, el papel que Aristóteles asigna a la música en su reflexión sobre la tragedia y en su relación con la kátharsis. Si todas las artes tienen en común el ser imitaciones y se diferencian en tres aspectos: los medios con que imitan, las cosas que imitan y las formas en que imitan; si, además, se tiene en cuenta que los seis elementos constitutivos de

2. Véase mi trabajo «Aristóteles y Nietzsche: dos aproximaciones a la tragedia a través del concepto de mímesis». En prensa.

3. Poética, 6, 1449 b, introd., trad. y notas de T. Martínez Manzano y L. Rodríguez Duplá, Madrid: Gredos, 2011, p. 44. (He modificado ligeramente la traducción de acuerdo con la que propone en sus escritos T. Calvo). Las referencias a página son a esta edición.

4. En el capítulo 6 de la Poética, cuando Aristóteles distingue seis elementos constitutivos o cualitativos de la tragedia, los clasifica así por orden de importancia: argumento, caracteres, pensamiento, dicción, canto y puesta en escena. Entre todos subraya la importancia del primero: El argumento, señala, «es el principio y como el alma de la tragedia» (Poética, 6, 1450 a, pp. 46-47).

5. Cf. Poética, caps. 1,2 y 3. 
la tragedia son, por orden de importancia, argumento, caracteres, pensamiento, dicción, canto y puesta en escena, resulta que, si «cruzamos» las seis partes de la tragedia con los tres aspectos señalados al inicio, tenemos que los medios con que se imita son dicción y canto; el modo o la forma en que se imita, la puesta en escena, y el objeto de la imitación viene dado por el argumento, los caracteres y el pensamiento ${ }^{6}$. En este punto cabe señalar dos cosas: primero, el papel secundario de la música respecto al argumento, los caracteres, el pensamiento y la dicción. La música (el canto, para decirlo con precisión) es un «adorno», un acompañamiento, un medio para la imitación); en suma, un ingrediente importante, pero no la base ni el elemento fundamental en la génesis de la tragedia, como sostendrá más tarde Nietzsche. Antes que ella incluso está la dicción y solo le sigue la puesta en escena; es verdad que en todos los casos se trata de elementos constitutivos de la tragedia, pero hay que insistir en el papel secundario de la música en la tragedia respecto de la mayor parte de sus elementos.

Con todo, conviene recordar que Aristóteles ofrece importantes reflexiones sobre la música en el libro VIII de la Política, en los capítulos 5, 6 y 7, en los que se refiere a la educación de los jóvenes y a los contenidos de la misma. De tales contenidos forma parte la educación musical. Y en este punto es importante la distinción que lleva a cabo al final del capítulo 7 respecto de los modos musicales. Allí distingue varios tipos: frigio (orgiástico y pasional, apropiado, como la flauta, para representar el delirio báquico y la agitación emotiva. Parece ser que en él tuvo su cuna el ditirambo); dorio (de armonía más firme y que presenta un carácter varonil, además de representar el término medio entre los extremos. Es el más apropiado para la educación de los jóvenes), y lidio (que, por su capacidad de implicar a la vez orden y educación, es el más indicado para la edad infantil) ${ }^{7}$. Volveremos más adelante sobre esto y sobre la cuestión concreta de la relación entre música y kátharsis, ahora conviene plantear el tema central de esta reflexión: si la tragedia es imitación (mimesis) y si dicha imitación es aprendizaje y conocimiento (epistéme), ¿̇cómo se relaciona este aprendizaje con la kátharsis?

\section{2. Objeto y medios de aprendizaje}

Si la tragedia es imitación (mimesis) y conocimiento (epistéme), cabe preguntar sobre qué versa ese aprendizaje y qué medios se utilizan para el mismo. En cuanto al objeto de aprendizaje, Aristóteles considera que la tragedia es «imitación de una acción seria» (spoudaias), pero no hay unanimidad acerca de la traducción al castellano de ese término. "Seria» es la versión castellana de ese término que ofrece la edición que venimos usando; «seria» es también la traducción elegida por T. Calvo en su trabajo sobre el concepto de tragedia en Aristóteles ${ }^{8}$; por su parte, Kaufmann, en su obra Tragedia y filosofía, prefiere usar el vocablo «noble»",

6. Poética, 1450a, p. 45.

7. Política, 1342b, ed. bilingüe y trad. de J. Marías y M. Araujo, introd. y notas de J. Marías, Madrid: Centro de Estudios Constitucionales, 1983, p. 164.

8. Cf. T. Calvo Martínez, La visión de la tragedia en Aristóteles, inédito, 2014 (8pp.), p. 7. Quiero agradecer al profesor T. Calvo que me haya permitido acceder a este trabajo suyo aun cuando todavía no ha sido publicado.

9. Cf. W. Kaufmann, Tragedia y filosofía, trad. de S. Oliva, Barcelona: Seix Barral, 1978, pp. 80 y 81 . 
y Redfield, que usa también el término «serio», cuando traduce la definición aristotélica de tragedia, a veces lo vierte por «excelente» ${ }^{10}$. En todo caso hay algo en lo que parece haber acuerdo: en la tragedia se trata siempre de una acción «no trivial», de una acción significativa y de importancia para el ser humano, pues parece que la enseñanza de que se trata en la tragedia tiene que ver con la vida, con la vida del hombre y con lo que es verdaderamente significativo para él. Como señala el profesor Calvo, «se trata de acciones en que se juega mucho, tanto la felicidad y la desgracia de la vida humana ${ }^{11}$. Pero también de acciones en las que cualquier hombre puede reconocerse. Tal vez ese doble hecho explique por qué Aristóteles considera a Eurípides «el más trágico de todos los poetas»: porque, en primer lugar, en sus obras se narra el paso de la felicidad a la desgracia ${ }^{12}, \mathrm{y}$, luego, porque Eurípides representa a los hombres tal como son ${ }^{13}$.

En fin, si lo representado en la tragedia atrae vivamente el interés del espectador, si los acontecimientos dolorosos que allí se contienen resultan estimulantes e incluso placenteros, es porque tienen que ver con nosotros y porque mediante ellos aprendemos algo fundamental acerca de la vida y de nosotros mismos, algo fundamental acerca de la condición humana. La tragedia permite, pues, un acceso a la verdad, a la verdad de la vida, aunque no sea directamente, sino mediante el «rodeo» de la ficción. Como dice Redfield, «las cosas que leemos solo merece la pena leerlas en la medida en que encontramos en ellas, en cierto modo, la verdad». Hay, por tanto, una verdad en el arte, en el relato, en la tragedia, pero la verdad que muestra la tragedia es de un tipo especial, una verdad «severa e incómoda $»^{14}$, una verdad que refiere aquellos aspectos de la vida que son, al mismo tiempo, profundos y oscuros: «la tragedia es dolorosa porque la vida es difícil» ${ }^{15}$.

Tal vez es eso lo que quiere decir Aristóteles, cuando señala que se trata de la «imitación de una acción seria». Pero también ahí, como ha señalado lúcidamente Redfield, radica su distancia con el conocimiento teórico que proporciona la ciencia y con el conocimiento práctico asociado a la moral. El artista se diferencia del científico en que mientras este último explica el todo en función de sus partes y los efectos en función de causas características, aquel no aspira a explicar lo que ocurre: «Si bien el placer del arte imitativo consiste en un aprendizaje, el artista no por eso se convierte en un maestro. No nos explica nada. Más bien nos plantea un problema resoluble, un problema que siempre puede volver a ser resuelto de alguna forma nueva la siguiente vez que se plantee» ${ }^{16}$. Pero también se diferencia del moralista: el artista no dice cómo deben ser las cosas, sino cómo son: «La ética opera del actor hacia la acción y prescribe; dice que tal hombre debe vivir de tal

10. J. M. Redfield, La tragedia de Héctor. Naturaleza y cultura en la Ilíada, Barcelona: Destino, 1992, p. 159.

11. T. Calvo, op. cit., p. 4.

12. Poética, 1453a, p. 57: «Por eso, no tienen razón quienes reprochan a Eurípides que haga esto en sus tragedias y que la mayoría de ellas acabe en desgracia. Pues esto es lo correcto y Eurípides es el más trágico de los poetas».

13. Poética, 1460 b, p. 88 : «Puesto que el poeta es un imitador, como lo es el pintor o cualquier otro autor de imágenes, hay que imitar siempre una de estas tres cosas: o bien las cosas como eran o son, o bien como se dice o se cree que son, o bien como deben ser».

14. J. M. Redfield, op. cit., pp. 19-22.

15. Ibid., p. 168.

16. Ibid., p. 112. 
modo y qué es lo bueno. La ficción opera de la acción hacia el actor y describe; muestra que tal acción humana hubiera podido ser hecha por tal hombre, que eso es probable; presenta ejemplos concretos de felicidad y desgracia, de tal modo que se vean las relaciones causales entre el actor, su situación y el acontecimiento» ${ }^{17}$.

Conviene detenerse ahora en la consideración de los medios que usa el poeta trágico para llevar a cabo su enseñanza. La tragedia «debe imitar los sucesos temibles y dignos de compasión», leemos en el capítulo 13 de la Poética ${ }^{18}$. Esas dos emociones habían sido ya destacadas en el capítulo 6, allí se señalaba su capital importancia en la obra de arte trágica. Y también en el capítulo 9, donde se advertía que «la imitación no debe ser solo de una acción completa, sino también de hechos que suscitan temor y compasión. Y esto ocurre cuando las cosas suceden de forma inopinada, pero unas a causa de otras» ${ }^{19}$. Por su parte, el capítulo 11 destacaba que «reconocimiento y peripecia llevan consigo compasión y temor y la buena o mala fortuna están en función de esas cosas ${ }^{20}$. Pero, sobre todo, los capítulos 13 y 14 contienen importantes consideraciones para aclarar la importancia y la significación de tales pasiones en Aristóteles. El capítulo 13 considera los medios gracias a los cuales se alcanza el efecto de la tragedia: esta debe ser compleja (no simple) e imitar sucesos temibles y dignos de compasión ${ }^{21}$. Y en el capítulo 14 , se dice que el temor y la compasión deben surgir, no de la puesta en escena, sino del entramado de los hechos. Es preciso que lo experimente no solo quien asiste a la representación, sino el que escuche el argumento; por el contrario, cuando temor y compasión dependen de la puesta en escena esto es «menos propio del arte y requiere gastos para el montaje». Y añade que en la tragedia no hay que buscar todo tipo de placer, sino el que le es propio y este parece derivarse de la compasión y el temor ${ }^{22}$. Aristóteles se refiere escuetamente a ellas en la Poética, donde advierte que «la compasión se refiere a quien es desgraciado sin merecerlo y el temor a quien es semejante a nosotros ${ }^{23}$. Una consideración más detallada se encuentra en la Retórica, pero de momento no es imprescindible para nuestras reflexiones sobre los efectos de la tragedia.

\subsection{El conocimiento emotivo}

Acabamos de señalar que, según Aristóteles, «no hay que buscar en la tragedia todo tipo de placer, sino el que le es propio». Pero équé placer le es propio y en qué consiste el conocimiento peculiar que se obtiene mediante la tragedia? Se trata, como se verá, de preguntas equivalentes, a las que cabe dar respuesta desde el significado de la kátharsis en Aristóteles. En el capítulo 14 de la Poética encontramos la siguiente reflexión:

Los que mediante la puesta en escena procuran no solo lo temible, sino también lo prodigioso, nada tienen que ver con la tragedia, pues no hay que buscar en la tragedia todo tipo de placer, sino el que le es propio. Puesto que el poeta debe proporcionar

17. Ibid., pp. 126-127.

18. Poética, 1452 b, p. 56.

19. Poética, 1452a, p. 52.

20. Poética, 1452a, p. 54.

21. Poética, 1452 b, p. 56.

22. Poética, 1453b, p. 58.

23. Poética, 1453a, p. 56. 
por medio de la imitación el placer derivado de la compasión y el temor, es evidente que ello ha de estribar en los hechos ${ }^{24}$.

Aristóteles acentúa de nuevo el valor de la acción frente a la puesta en escena, para que no quepa ninguna duda de que es la imitación de la acción (mimesis y praxis) y concretamente la trama, el argumento (mythos), lo que constituye el alma y el fin de la tragedia, y es también allí donde debe estribar el placer que le es propio a la tragedia. Pero, ¿de qué placer se trata y en qué consiste? Conocemos su nombre, la kátharsis, aunque no resulta tan evidente en qué pueda consistir.

El único lugar de la Poética en que Aristóteles se refiere expresamente a ella es el capítulo 6, en la referida definición de la tragedia: la tragedia «lleva a cabo mediante la compasión y el temor la purificación (kátharsis) de pasiones tales» 25 . Ya la traducción del término por «purificación» supone una carga interpretativa que no está en absoluto fuera de discusión y, aunque no entraremos de lleno en ella, conviene hacer una breve referencia a las principales corrientes interpretativas de dicho concepto aristotélico.

Por lo pronto llama la atención que Aristóteles sea tan parco en su explicación, tanto más cuanto que en la Política remite a la Poética para su aclaración. En el capítulo 7 del libro VIII y refiriéndose a la música, señala que «no debe estudiarse porque proporcione un solo beneficio, sino muchos, pues debe cultivarse con vistas a la educación y la purificación (cuando tratemos de la poética explicaremos con más claridad qué queremos decir con el término purificación, que ahora empleamos simplemente); en tercer lugar, debe cultivarse también como divertimiento y como solaz y descanso tras el esfuerzo» ${ }^{26}$.

Es sabido que la Poética no ha llegado a nosotros como un texto completo y hay que suponer que la parte dedicada a la aclaración de ese concepto (así como seguramente la parte dedicada a un estudio más exhaustivo de la comedia) se perdió. Pero, por lo que respecta a la música y a su relación con la kátharsis, Aristóteles lleva a cabo una interesante reflexión en la Política. Justo después del texto que se acaba de referir y hasta el final del libro, señala que debemos servirnos de todas las melodías, pero no de todas en el mismo sentido. Para la educación solo hay que servirse de «las más éticas», pero para la audición, como espectáculo, «también de las prácticas y las entusiastas».

Pues las emociones que en algunas almas revisten mucha fuerza, se dan en todas, con diferencias de grado, como la compasión, el temor y el entusiasmo.

Algunos incluso tienen propensión a dejarse dominar por este último y vemos que cuando usan las melodías que arrebatan el alma, la música sagrada les afecta como si encontraran en ella curación y purificación. Esto mismo tienen que experimentar necesariamente los que están poseídos de compasión o de terror, o, en general, de cualquier pasión, y los demás, en la medida que esté afectado cada uno por esos sentimientos, y en todos se operará cierta purificación y alivio acompañado de placer ${ }^{27}$.

De este importantísimo texto es preciso destacar algunas cosas. En primer lugar, que las melodías producen (o reproducen) las emociones que afectan al alma

24. Poética, 1453 b, p. 58.

25. Poética, 1449b, p. 44.

26. Politica, 1342 a, p. 163.

27. Ibid. (la cursiva es nuestra). 
con diferencias de intensidad y aquí se destacan tres principales: la compasión, el miedo (el temor) y el entusiasmo. Segundo, que aquellos que son propensos a la influencia de las emociones, muy especialmente a la emoción del entusiasmo, se encuentran como arrebatados y hallan en la música «curación y purificación». Finalmente, $\mathrm{y}$ en tercer lugar, que esa misma experiencia vale para todos aquellos que experimenten tales emociones y, en general, cualquier pasión, y que a tal experiencia purificadora se asociará la de un alivio placentero («en todos se operará cierta purificación y alivio acompañado de placer»).

Estas consideraciones y el uso de la conjunción «y» para unir términos tales como «purificación» $\mathrm{y}$ «curación», "purificación» $\mathrm{y}$ «alivio acompañado de placer», juegan a favor de la interpretación médica del término kátharsis, como ya hizo Bernays ${ }^{28}$. Pero el hecho de que en la Poética, al menos tal como ha llegado a nosotros el texto, no se aclare nada sobre el término, ha alentado la polémica en torno a la interpretación del mismo ${ }^{29}$.

Cabe destacar dos interpretaciones clásicas sobre el sentido de la kátharsis trágica en Aristóteles. Está por un lado, la interpretación «intelectualista» que la entiende como "purificación» en el sentido religioso de "expiación de una culpa", de represión o, al menos, de moderación de tales fenómenos emocionales (entre otros, esta interpretación ha sido defendida con diversos matices por P. Vettori, A. Piccolomini, Lessing y también por Else). Pero, como señala T. Calvo ${ }^{30}$, esta interpretación parece pasar por alto algunos aspectos vivenciales y de descarga que el propio Aristóteles destaca, como se ve en el texto referido de la Política. Por otro lado, está la interpretación de la kátharsis trágica en un sentido médico, psicoanalítico, o terapéutico, que la entiende como «purgación» o descarga emocional a la que sigue un sentimiento placentero de alivio. A este respecto señala Kaufmann que así como Platón habló de la poesía de manera poética, Aristóteles lo hace como médico, de modo que «el placer de la tragedia refiere el efecto placentero de alivio» ${ }^{31}$. Esta interpretación ha sido defendida muy especialmente por Bernays, que influyó sin duda en la interpretación nietzscheana, pero también por Schadewalt y Grube entre otros. De acuerdo con ella, no se trata tanto de reprimir o moderar estas pasiones, como de despertarlas, estimularlas o provocarlas para facilitar su descarga. Pero, como también advierte T. Calvo, estos sentimientos ni pueden ni deben erradicarse del todo ${ }^{32}$.

Creo que un aspecto clave en la resolución de este conflicto de interpretaciones estriba en el modo en que se entienda el genitivo en la definición que Aristóteles

28. En este punto resulta del mayor interés el estudio de G. Ugolini, Jacob Bernays e l'interpretazione medica della catarsi tragica, Verona: Cierre Grafica, 2012.

29. Sobre las distintas interpretaciones de este término, véase T. Martínez Manzano y L. Rodríguez Duplá, «Introducción», a Aristóteles, Poética, pp. 25 y 29. Además de los textos citados de T. Calvo, W. Kaufmann y G. Ugolini. En este mismo punto resultan de gran utilidad los estudios de C. Gentili, Ermenentica e Metodica. Studi sulla metodologia del comprendere, Genova: Marietti, 1996, pp. 295-336 y de M. Nussbaum, «La fortuna y las pasiones trágicas», en La fragilidad del bien, Madrid: Visor, 1995, pp. 469-487.

30. «Esta interpretación tiene el inconveniente de ignorar que tales sentimientos no pueden ser erradicados, ni es razonable que lo sean, en la medida en que forman parte de nuestro modo de comprender y de hacer frente a aspectos cruciales de la condición humana, de acuerdo con la psicología de Aristóteles» (T. Calvo, op. cit., p. 5).

31. W. Kaufmann, op. cit., p. 95.

32. T. Calvo, op. cit., pp. 4-5. 
ofrece de la tragedia. Se trata de la «imitación de una acción seria» que «mediante la compasión y el miedo logra la purificación de pasiones tales». ¿Cómo hay que entender la preposición «de»? ¿Quién o qué purifica? ¿Quién o qué debe quedar purificado ${ }^{33}$ ? En el caso de una interpretación subjetiva del genitivo, son las pasiones de la compasión y el miedo las que, experimentadas por el espectador, actúan como agentes de la kátharsis del mismo. En el caso de la interpretación objetiva del genitivo es el espectador el que queda liberado de tales pasiones experimentando la kátharsis o liberación de las mismas en la forma de un alivio placentero. Pero cabría ir más allá de la alternativa, y podría entenderse el genitivo en el doble sentido, objetivo y subjetivo.

Sobre esta base se abre una interesante vía interpretativa que, de un modo u otro, es sostenida por distintos intérpretes de Aristóteles y que arroja luz sobre una forma especial de conocimiento: el "conocimiento emotivo», que a nuestro juicio se encuentra insinuado en la reflexión aristotélica sobre la kátharsis. Así por ejemplo, T. Calvo, reflexionando sobre el modo de entender el genitivo, apunta la posibilidad de entenderlo en tal doble sentido, resultando así que son tales pasiones las que liberan y purifican al alma y, al mismo tiempo, las que resultan reconducidas a su forma no patológica, sino razonable y normal, «como mecanismos naturales de comprensión y de reacción, a la vez, ante lo que es constitutiva y verdaderamente serio respecto de la condición humana» ${ }^{34}$.

También Redfield propone en este punto una reflexión análoga y clarificadora. $\mathrm{Si}$, como se señalaba más arriba, «la tragedia es dolorosa porque la vida es difícil», a esto añade que «el poeta trágico escruta a fondo la vida y nos muestra la dura verdad que ve». Sin embargo, no puede tratarse de un puro reflejo neutro; a dicha reflexión ha de agregarse una importante matización. No todo el arte que evoca piedad y temor deberá calificarse como trágico: los pathémata no son más que mera experiencia, a menos que estén justificados por la enseñanza que los acompaña ${ }^{35}$. Y es verdad, si el arte fuese solo la exposición de las duras verdades de la vida, si solo mostrara su aspecto terrible, no pasaría de ser una crónica, como las que vemos día a día y nos sobrecogen. Se ve también por qué tendría razón Nietzsche cuando señala que el temor y la compasión son emociones depresivas que disminuyen o quitan el gusto por la vida, de forma que también Platón tendría razón al expulsar a los poetas de la ciudad. Lo que hace el poeta y el poeta trágico no es solo exponer y mostrar las duras verdades de la vida, sino elaborarlas hasta extraer de ellas una enseñanza y una enseñanza «vital» (en el doble sentido de esencial y de recaer sobre la vida). Si solo se tratara de un conocimiento emotivo (mediante la piedad y el miedo) y si no llevara a cabo unos efectos sobre tales emociones, no se vería su efecto beneficioso (catártico y purificador).

Basándose en Poética 1452 a1-4, Redfield señala que cuando los acontecimientos «contrarían las expectativas», cuando nos revelan una pauta de relaciones causales que no habíamos visto antes, entonces nos sentimos conmovidos y embelesados. De modo que los páthe peculiares de los argumentos no pueden separarse de su peculiar enseñanza. Páthe y enseñanza constituyen para nosotros el peculiar valor

33. Una interpretación exhaustiva de esto mismo y de las tres posibles interpretaciones sobre el plano gramatical se encuentra en G. Ugolini, op. cit., pp. 40 ss.

34. T. Calvo, loc. cit., p. 5.

35. J. M. Redfield, op. cit., p. 168. 
que tiene la narración bien hecha. Esta combinación de enseñanza y emociones es para Redfiel lo que Aristóteles quería decir con la kátharsis: la tragedia purifica la piedad y el temor mediante la piedad y el temor. Esto parece paradójico hasta que recordamos que la obra trágica es algo que al mismo tiempo experimentamos y conocemos ${ }^{36}$.

En la tragedia se trata, pues, de conocimiento y enseñanza, operado por las emociones y que recae sobre las emociones. Se trata de un conocimiento, pero no tiene un sentido únicamente teórico, sino que tiene como condición fundamental las emociones. Es un «conocimiento emotivo» en el sentido fuerte y doble de la expresión (conocimiento de las emociones en el doble sentido, subjetivo y objetivo, del genitivo). Pero es también un aprendizaje útil para la vida, para seguir viviendo una vida que, contemplada bajo el prisma del mero conocimiento, de una visión de los aspectos más dolorosos y difíciles de la existencia nos quitaría el gusto por ella. Como señala Redfield, «los pathémata son susceptibles de purificación precisamente porque, cuando los experimentamos en una obra de imitación, son modos de aprender más bien que experiencias desnudas ${ }^{37}$. Pero tal aprendizaje tiene el doble sentido de aclaración y terapia, de captación de un contenido y de aprovechamiento del mismo; «purificación» tiene el doble sentido intelectualista y terapéutico que hemos señalado antes, por eso, los pasajes de la Poética y el de la Política, aunque distintos, son coherentes: abordan la misma cuestión desde distintos puntos de vista y aluden respectivamente a dos aspectos, intelectual y terapéutico, de un único fenómeno. La Poética pone el acento en el significado, la Política en la experiencia inmediata; la primera habla de la poesía en tanto que conforma virtudes intelectuales, la segunda en tanto que conforma virtudes éticas. Pero Aristóteles siempre entiende que estas dos clases de virtudes son aspectos de una única personalidad y solo separables en el análisis ${ }^{38}$.

Debe, pues, subrayarse que el conocimiento es ya una forma de purificación, que hasta el conocimiento de lo más impuro, de lo desagradable y lo terrible, puede ser elevado y provocar el placer propio del conocimiento ${ }^{39}$. Hay que recordar que, de acuerdo con Aristóteles, «los animales más despreciables y los cadáveres», son cosas típicamente impuras o sin purificar y que, según el filósofo, sentimos placer en la imitación de esas cosas porque a través de la imitación aprendemos algo, de manera que tal vez el aprendizaje purifique de por sí. Y en este mismo aspecto de clarificación, que operan la compasión y el temor y que recae sobre ellos (el doble sentido, subjetivo y objetivo, del genitivo que estamos defendiendo), insiste M. Nussbaum ${ }^{40}$, que lleva a cabo un análisis filológico del término kátharsis y pone de relieve su significado de limpieza, clarificación y eliminación de obstáculos tales como suciedad, mancha, oscuridad o mezcla. Nussbaum señala que la tragedia contribuye al conocimiento de uno mismo explorando lo temible y lo que mueve a la piedad, una labor que realiza suscitando dichas pasiones, pero insiste en que

36. Cf. ibid., pp. 133-134.

37. Ibid., p. 410.

38. Cf. ibid., pp. 410-412.

39. «Mediante la imitación — dice Redfield — los acontecimientos se reducen a una forma y, de este modo, por impuros que sean en sí mismos, los acontecimientos representados se purifican —se clarifican - hasta ser inteligibles» (ibid., p. 410).

40. M. Nussbaum, La fragilidad del bien, cit., pp. 480-487. 
la clarificación que produce la kátharsis no significa, como en Platón, únicamente una clarificación intelectual. Lo novedoso de estas reflexiones respecto de Platón es, por una parte, que las pasiones mismas pueden llevarla a cabo, y, luego, que hay «respuestas emocionales que, como las buenas respuestas intelectuales, pueden contribuir al tipo de 'percepción' que constituye el mejor juicio humano». Las pasiones no solo pueden «deformar», sino también abrir un plano de comprensión más profundo. Aristóteles difiere de Platón no solo en lo tocante a los mecanismos de clarificación, sino también respecto a lo que es la clarificación en la persona buena. Pero, como concluye Nussbaum, «la función de la tragedia es lograr, por intermedio de la compasión y el temor, una clarificación (o iluminación) relacionada con las experiencias dignas de compasión y temibles» ${ }^{41}$.

\section{NIETZSCHE: LA TRAGEDIA COMO TÓNICO VITAL}

\subsection{La importancia de los inicios}

Las consideraciones de Nietzsche acerca de la tragedia y de lo trágico pueden dividirse en dos periodos: antes y después de 1876. En un primer momento Nietzsche denuncia la «perversión» sufrida por el concepto de lo trágico de manera especial a partir de Eurípides y Sócrates ${ }^{42}$, pero la decadencia se había iniciado mucho antes ${ }^{43}$ y en todo caso, a juicio de Nietzsche, las reflexiones de Aristóteles se insertan en una época en la que la tragedia había dejado de ser lo que era ${ }^{44}$. Nietzsche augura entonces un renacimiento de la tragedia en la cultura alemana, renacimiento que habrían hecho posible los planteamientos filosóficos de Kant y Schopenhauer y que con la música de Wagner prometían llegar a su cumplimiento efectivo. Más tarde, cuando en 1876 asista a los festivales de Bayreuth, experimentará una profunda desilusión y concluirá que las esperanzas depositadas en la filosofía de Schopenhauer y en la música de Wagner no tenían ningún fundamento y que allí donde había esperado un renacimiento de lo trágico solo había romanticismo y decadencia ${ }^{45}$.

Por lo que respecta a Aristóteles, al que Nietzsche se refiere repetidamente en El nacimiento de la tragedia, conviene recordar un interesante fragmento datado en 1875 en el que encontramos la siguiente afirmación: «El deseo de tener como fuese algo seguro en Estética indujo a la veneración de Aristóteles; creo que poco a poco va a ir demostrándose que Aristóteles no entiende nada de arte y que lo que admiramos en él solo es el eco de los sabios discursos de los atenienses» ${ }^{46}$. La distancia

41. Ibid., p. 483.

42. Sobre el nacimiento y muerte de la tragedia, véase mi libro El desafío del nibilismo y concretamente el capítulo titulado «La vida no vale nada», Madrid: Trotta, 2005, pp. 165-191.

43. G. Ugolini, «Nietzsche contra Aristotele. La Nascita della tragedia e la Poetica», en M. C. Fornari, Edizioni e interprtetationi, ETS, Pisa, 2006, p. 398.

44. Véase F. Nietzsche, «El drama musical griego», en El nacimiento de la tragedia, trad. de A. Sánchez Pascual, Madrid: Alianza, 1985, p. 205. Nietzsches Kritische Studienausgabe, ed. de G. Colli y M. Montinari, Berlin: Walter de Gruyter, 1967-1988 (en adelante, KSA), 1, pp. 524-525.

45. He estudiado esta temática en mi trabajo «Nietzsche y el hada maligna del romanticismo», en G. Campioni, L. Pica Ciamarra y M. Segala (eds.), Goethe Schopenhauer Nietzsche, ETS, Pisa, 2012, pp. 13-26.

46. Fragmento 5 [13] Primavera-verano de 1875, en Fragmentos Póstumos (1875-1882), vol. II, trad., introd. y notas de M. Barrios y J. Aspiunza. Tecnos, Madrid, 2008, p. 66 (KSA, 8, 43). 
respecto de Aristóteles resulta evidente y se entiende que Nietzsche (que no sabemos si fue un lector atento de la Poética, pero que si lo hubiese sido, no cabe duda de que no fue un lector entusiasta) no siguiera sus pasos en su interpretación de la tragedia. Esta oposición ha sido muy estudiada, pero de entre los estudios recientes quisiera destacar dos de G. Ugolini: uno, sobre la interpretación nietzscheana de la noción aristotélica de kátharsis trágica, descubre importantes aspectos de esa relación, tomando como referencia la lectura de Bernays. El otro ofrece una comparación exhaustiva de los aspectos más relevantes en los que Nietzsche y Aristóteles resultan enfrentados, siendo la reflexión nietzscheana una suerte de "antipoética»" ${ }^{47}$. Estas referencias resultan de gran utilidad y se han tenido en cuenta en este estudio, pero en lo que sigue desearía poner de manifiesto no solo las diferencias entre los dos autores, sino también algunos paralelismos.

Ciertamente las posiciones respectivas en torno a la tragedia de estos dos pensadores son muy diferentes. Aristóteles respondía a Platón, para quien la filosofía constituye una alternativa pedagógica a la poesía, pero su reflexión se encuadra en un momento en que el discurso filosófico estaba bien asentado y reconocido, y no tenía que defender ni justificar su puesto como saber. Si la filosofía se considera el saber por antonomasia, las artes también son saberes, aunque de otra naturaleza y de menor rango y Aristóteles reconoce que filosofía y poesía son compatibles y conviven en el marco referencial de la pólis. Su Poética, reconocida tantas veces como el primer tratado de crítica literaria, podría interpretarse como un discurso crítico-normativo, pero también como un discurso médico-psicológico, que reconoce los efectos positivos y beneficiosos de la tragedia. En cambio, la reflexión de Nietzsche es de otro calado y, en cierto modo, está más cerca de Platón que de Aristóteles, aunque sus conclusiones sean contrarias a las de aquel.

En líneas generales, para comprender las posiciones respectivas de Aristóteles y Nietzsche, resulta muy útil recordar la reflexión de W. Kaufmann. A juicio de este, no hay necesidad de reavivar el mito según el cual se es platónico o aristotélico; sencillamente Aristóteles fue en este campo temático más lejos que Platón y nosotros debemos ir más lejos que ellos ${ }^{48}$. Por nuestra parte, preguntamos si es posible ir más lejos y, en todo caso, si Nietzsche lo fue. Kaufmann señala con razón que Aristóteles no consideraba la tragedia como una de las glorias más altas del espíritu humano, ni pensaba que los filósofos pudiesen aprender mucho de los poetas trágicos; reaccionó contra sus predecesores y en lugar de tratar a los poetas trágicos como rivales que tienen puntos de vista fascinantes y diferentes de los propios y de los demás filósofos, ignoró sus ideas y se preocupó de su técnica, estableciendo así una nueva disciplina: la poética o, en todo caso, una estética ${ }^{49}$. Por lo que respecta a Nietzsche, en lo que sigue intentará mostrarse que sostiene una concepción trágica de la vida y en esto, a pesar de todas las diferencias, resulta más próximo a la sensibilidad de Platón, que consideraba a los poetas trágicos como rivales en su tarea de paideia. Nietzsche se acercó a la tragedia no desde un punto de vista técnico, sino filosófico y, sobre todo, vital, pues el arte, y el arte trágico en particular, no era para él una tarea entre otras de la vida, sino la más alta y la fundamental.

47. Se trata de los trabajos ya citados: «Nietzsche contra Aristotele. La Nascita della tragedia e la Poetica» y Jacob Bernays e l'interpretazione medica della catarsi tragica.

48. Véase W. Kaufmann, op. cit., p. 128.

49. Ibid., pp. 126 y 127. 
Además, se acercó a los griegos buscando en ellos el verdadero magisterio en esta tarea, sobre todo a los antiguos griegos, a aquellos que precedieron a Sócrates y Platón y también a Eurípides. En este punto, frente a Aristóteles, para quien este último era «el más trágico de los poetas» ${ }^{50}$, Nietzsche sostuvo que lo mejor ya se había producido, que era lo más lejano en el tiempo, pero que si alguna vez fue, podría otra vez volver a repetirse: «... lo que nosotros esperamos del futuro, eso ha sido ya una vez realidad - en un pasado de hace más de dos mil años» ${ }^{51}$.

\subsection{La singularidad del placer estético}

Nietzsche no puso nunca en duda que la tragedia revela un aspecto de las cosas para el que solo ella resulta un acceso adecuado y que ese aspecto, inhóspito y oscuro, también solo ella misma era capaz de hacerlo soportable. Mimesis y kátharsis, los dos elementos fundamentales que hemos destacado a propósito de Aristóteles, tienen su equivalente en la reflexión nietzscheana, sobre todo si se tienen en cuenta dos aspectos destacados por Nietzsche: por un lado, la importancia de «lo feo y lo disarmónico»; por otro, el papel de la música y del coro en el origen de la tragedia ática. Con respecto a esto último, es imposible obviar el hecho de que cada uno le asigne un papel muy diferente: para Aristóteles muy secundario y, en cambio, de importancia capital en Nietzsche. Detengámonos en esos dos aspectos apuntados. Un texto de El nacimiento de la tragedia nos servirá como referencia:

... ¿̇de dónde procede aquella tendencia, en sí enigmática, a que el sufrimiento que hay en el destino del héroe, las superaciones más dolorosas, las antítesis más torturantes de los motivos, en suma, la ejemplificación de aquella sabiduría de Sileno, o, expresado en términos estéticos, lo feo y disarmónico, sean representados una y otra vez de nuevo, en formas tan innumerables, con tal predilección, y cabalmente en la edad más pujante y juvenil de un pueblo, si justo en todas esas cosas no se percibe un placer superior? ${ }^{52}$.

En un trabajo anterior ya referido sobre el significado de mimesis en Aristóteles y Nietzsche ${ }^{53}$ se aludió al valor de lo «disarmónico y lo feo», pero interesa ahora referirlo a otro aspecto clave de la tragedia: el mito trágico y la música. ¿̇or qué no solo existe una tendencia (y un placer) en la representación de la belleza y la armonía, sino también en la representación de lo feo y lo disarmónico? Tal vez en la respuesta a esta pregunta sea posible, contra lo esperado, encontrar una prolongación o, por lo menos una cierta sintonía en los planteamientos respectivos de Aristóteles y Nietzsche. Por lo pronto, Nietzsche formula la misma pregunta planteada a propósito de Aristóteles: ¿̇en qué consiste el placer peculiar de la tragedia? En el capítulo 24 de El nacimiento de la tragedia encontramos esta importante reflexión que, no obstante su longitud, conviene reproducir por entero:

Yo pregunto por el placer estético, y sé muy bien que muchas de esas imágenes pueden producir además, en ocasiones, un deleite moral, por ejemplo en forma de compasión

50. Poética, 1453a, p. 57.

51. El drama musical griego, cit., p. 212 (KSA 1, 532).

52. El nacimiento de la tragedia, cit., p. 187 (KSA 1, 151). (La cursiva es nuestra).

53. Véase supra, nota 2. 
o de triunfo moral. Mas quien el efecto de lo trágico quisiera derivarlo únicamente de esas fuentes morales, como solía hacerse en la estética no hace mucho tiempo, no crea que con eso ha hecho algo por el arte: el cual, en su campo, tiene que exigir ante todo pureza. Para aclarar el mito trágico la primera exigencia es cabalmente la de buscar el placer peculiar de él en la esfera estética pura, sin invadir el terreno de la compasión, del miedo, de lo moralmente sublime. ¿Cómo lo feo y lo disarmónico, que son el contenido del mito trágico, pueden suscitar un placer estético?

Aquí se hace necesario elevarse, con una audaz arremetida, hasta una metafísica

del arte, al repetir yo mi anterior tesis de que solo como fenómeno estético aparecen justificados la existencia y el mundo: en ese sentido, es justo el mito trágico el que ha de convencernos de que incluso lo feo y disarmónico son un juego artístico que la voluntad juega consigo misma, en la eterna plenitud de su placer. Este fenómeno primordial del arte dionisíaco, difícil de aprehender, no se vuelve comprensible más que por un camino directo, y es aprehendido inmediatamente en el significado milagroso de la disonancia musical: de igual modo que en general es solo la música, adosada al mundo, la que puede dar un concepto de qué es lo que se ha de entender por justificación del mundo como fenómeno estético. El placer que el mito trágico produce tiene idéntica patria que la sensación placentera de la disonancia en la música. Lo dionisíaco, con su placer primordial percibido incluso en el dolor, es la matriz común de la música y del mito trágico 54.

Así pues, Nietzsche, como Aristóteles, se pregunta por el «placer peculiar» que ofrece el mito trágico, pero a diferencia de él, advierte que se trata de un placer que hay que buscar en la esfera estética pura, más allá de la moral, de la compasión y de lo sublime. Y en ese placer estético puro sitúa una metafísica del arte que justifica la existencia y el mundo como «fenómeno estético» y que engloba no solo la belleza y la armonía, sino también «lo feo y lo disarmónico». Obsérvese que allí tiene un papel destacadísimo la música y que desde ella, desde la armonía y la disonancia, se explican tanto la belleza como su opuesto. Y, sin embargo, ni siquiera la música es lo último, sino lo dionisíaco, la experiencia de unidad que engloba todo y que evoca el placer en medio del sufrimiento, esa es la matriz común de la música y del mito trágico: lo dionisíaco es para Nietzsche el acto de afirmación suprema de la vida, de esta vida, la verdadera vida.

Lo dionisíaco es también la superación de lo individual, la expresión de una voluntad que va más allá del artista, del actor y el espectador. Nietzsche niega que el arte tenga un fin moral, el de «formarnos o mejorarnos»; niega también que el artista como tal sea "el verdadero creador de ese mundo»: el artista es solo un médium a través del cual «el único sujeto verdaderamente existente festeja su redención en la apariencia» y su acción creativa no es propiamente un acto de creación, sino de "procreación artística», pues solo en la medida en que se fusiona con aquel «artista primordial del mundo» es a la vez «poeta, actor y espectador». El único «artista primordial» es el Uno, simbolizado por Dionisos, desmembrado en infinitas apariencias, cuyo conjunto es el mundo, ese gran teatro donde la división en poeta, actor, espectador es una división arbitraria, ilusoria y sin fundamento, una división desorientadora que en absoluto ayuda a conocer la auténtica realidad de las cosas, porque lo único real es el todo, el todo que está

54. El nacimiento de la tragedia, cit., p. 187 (KSA 1, 151). (La cursiva es nuestra). 
«más allá» de las divisiones que solo tienen valor para nosotros y para organizar provisionalmente nuestro mundo liviano y de corta duración en placer/dolor; verdadero/falso; bien $/ \mathrm{mal}^{55}$.

Nietzsche subraya que la verdad dionisíaca se adueña del ámbito entero del mito y lo usa como simbólica de sus conocimientos y que, más tarde, mediante la tragedia, alcanza el mito su contenido más hondo, su forma más expresiva. Ella es símbolo de lo dionisíaco, expresión de una realidad mítica que está destinada a marchitarse en la sistematización dogmática de la religión ${ }^{56}$. En la tragedia antigua anterior a Eurípides, el único protagonista es Dionisos: todos los personajes son solo máscaras de ese dios y todos los temas no son sino variantes de los sufrimientos de Dionisos ${ }^{57}$. Cuando más tarde Eurípides ofrezca sus obras al público, uno de los síntomas de la decadencia y fin de la tragedia, y no el menos importante por cierto, será el cambio de naturaleza del héroe, es decir, del actor, del protagonista. Ahora es el espectador el que salta a la escena, el protagonista de las tragedias de Eurípides representa al hombre común, en el que el espectador puede reconocerse. Y es inevitable recordar en este punto la teoría de Aristóteles sobre la «simpatía» que suscita el drama representado en la escena: el reconocimiento de un parentesco esencial entre el actor y el espectador, que Nietzsche, por su parte, rechaza de plano. Volveremos sobre este importante aspecto y sobre la comparación entre los dos pensadores en otro lugar, ahora interesa señalar que la tragedia debe su origen al sentimiento de lo dionisíaco y que al principio fue coro y nada más que coro, añadiéndose la acción mucho más tarde, con la introducción del diálogo:

... la tragedia antigua era pobre de acción y de tensión: incluso puede decirse que en sus etapas evolutivas anteriores no tenía puestas sus miradas en modo alguno en el obrar, el drama, sino en el padecer, el páthos. La acción se añadió cuando surgió el diálogo: e incluso en la época de florecimiento del drama el obrar verdadero y serio no fue presentado en escena descubierta. Qué otra cosa fue originariamente la tragedia más que una lírica objetiva, una canción cantada partiendo del estado de determinados seres mitológicos, y, además, con el traje de los mismos. Al principio un coro ditirámbico de varones disfrazados de sátiros y silenos tenía que dar a entender qué era lo que le había excitado de tal modo: aludía a un rasgo, rápidamente comprensible para los oyentes, de la historia de las luchas y sufrimientos de Dionisos ${ }^{58}$.

El contraste con Aristóteles es evidente. Ya no se trata, al menos al inicio, de la «imitación de una acción», sino en todo caso de un páthos. Además, la música tenía un papel primordial: originariamente la tragedia no fue otra cosa que «una canción cantada», «un coro ditirámbico»y, sobre todo, trataba de «la historia de las luchas y sufrimientos de Dionisos».

Una vez más, lo dionisíaco. Dionisos dominando la escena y en cierto modo dominando también la reflexión filosófica nietzscheana, que siempre permanecerá fiel a este hallazgo hasta considerarlo el mérito y distintivo fundamental de su filosofía. Quince años después de la publicación de su primera obra, en el Ensayo

55. Cf. ibid., pp. 66-67 (KSA 1, 47-48).

56. Cf. ibid., pp. 98-99 (KSA 1, 73-74).

57. Cf. ibid., pp. 96-97 (KSA 1, 71).

58. El drama musical griego, cit., p. 207 (KSA 1, 527-528). 
de autocrítica de 1886, reconoce como mérito fundamental de aquella el haber encontrado una respuesta a la pregunta ¿̇qué es lo dionisíaco? y haber descubierto en ese fenómeno la raíz del mito trágico y de la tragedia, en definitiva, de una filosofía trágica, caracterizada por la afirmación incondicional de la vida y opuesta frontalmente a cualquier interpretación moral del mundo ${ }^{59}$.

\section{3. El efecto tónico de la tragedia}

Nietzsche defiende un terreno propio para el arte y afirma que el placer estético es de un género especial y nada tiene que ver con el sentimiento moral que pueda en ocasiones acompañar a la representación artística. El placer estético no proporciona un deleite moral ni el valor de la obra de arte se mide por sus enseñanzas morales; lo propio del arte consiste en su capacidad de elevarse por encima de la moralidad hasta justificar la existencia misma incluso en sus aspectos más extraños y sombríos. Esta justificación o afirmación de la vida, incluye «lo feo y lo disarmónico», es decir, los aspectos más dolorosos de la existencia. Para el verdadero arte, «nada es superfluo», nada es reprobable. Eso es justamente lo que lo eleva por encima de la moralidad.

Pero eso explica también su efecto tonificante. Para entenderlo es preciso recordar que esta visión que Nietzsche ofrece de la tragedia antigua es muy particular y está también muy alejada del concepto común y clásico de la misma, incluido el que Aristóteles sostenía en su Poética. Tres elementos significativos al respecto, la singularidad del actor, el espectador y el poeta, que Nietzsche refiere en la conferencia titulada El drama musical griego, uno de los escritos preparatorios de El nacimiento de la tragedia, dan idea de la importancia y la magnitud de estos cambios.

Con respecto al actor, hay que señalar que en la tragedia antigua no se trata de un personaje, de un protagonista, de un héroe individual en torno al cual girase el drama. No era así al menos en los comienzos, lo que lleva a Nietzsche a afirmar que Esquilo y Sófocles permanecen desconocidos para nosotros en lo fundamental: solo nos son conocidos como poetas del texto, como libretistas, es decir, precisamente nos son desconocidos ${ }^{60}$. Bajo el nombre de «actor» hay que entender, por el contrario, un grupo, un grupo que actúa a plena luz del día, que recita, canta y se acompaña de la flauta ${ }^{61}$ (y en este punto resulta inevitable apuntar el paralelismo con lo que dice Aristóteles al respecto en el libro VIII de la Política).

En cuanto al espectador, el oyente, como lo llama Nietzsche, no hay que pensar en alguien que buscara en el espectáculo un entretenimiento, ni una huida de las ocupaciones y preocupaciones cotidianas. Es verdad que la tragedia no tiene nada que ver con lo cotidiano, pero tampoco con un divertimento que aleje de la seriedad y la profundidad de la vida. El oyente participaba «de un estado de ánimo festivo» ansiado durante largo tiempo, un estado de ánimo similar a las fiestas primaverales, que han seguido evocando las fiestas y mascaradas de carnaval; un estado de ánimo que tiene como resultado, más que un simple entretenimiento, un «salir fuera

59. «Ya en el 'Prólogo a Richard Wagner' el arte —y no la moral— es presentado como la actividad propiamente metafísica del hombre; en el libro mismo reaparece en varias ocasiones la agresiva tesis de que solo como fenómeno estético está justificada la existencia del mundo» («Ensayo de autocrítica» a El nacimiento de la tragedia, cit., p. 31 (KSA 1, 17).

60. El drama musical griego, cit., p. 197 (KSA 1, 517).

61. Véase ibid., pp. 199-200 (KSA 1, 519). 
de sí», un éxtasis en el que uno deja de ser el que cotidianamente es para ingresar en otro ser, o diluirse en el todo ${ }^{62}$.

Por lo que respecta al poeta, este último tenía que someterse escrupulosamente a unas reglas estrictas y apenas contaba con libertad ni siquiera en el asunto representado en la escena, que era el mismo una y otra vez. Su carácter fundamental no estriba en la autoría de una trama nueva y original, sino en el efecto que debía producir el coro ${ }^{63}$.

El contraste con Aristóteles surge de nuevo, pero donde resultará definitivo es en lo que respecta a los efectos que este espectáculo despierta y en los que en última instancia realizará su fin. En este punto Nietzsche tiene conciencia de alentar una nueva perspectiva y se refiere expresamente a las dos interpretaciones más comunes del fenómeno de la kátharsis en el capítulo 22 de El nacimiento de la tragedia, cuando apunta «que los filólogos no saben bien si han de ponerla entre los fenómenos médicos o entre los morales» ${ }^{64}$. Ninguna de ellas le convence y ambas son rechazadas por igual, denunciando que nunca desde Aristóteles se ha dado una explicación del «efecto trágico» y nunca tampoco se ha tenido de la tragedia una experiencia como «arte supremo»:

Nunca, desde Aristóteles, se ha dado todavía del efecto trágico una explicación de la cual haya sido lícito inferir unos estados artísticos, una actividad estética de los oyentes. Unas veces son la compasión y el miedo los que deben ser llevados por unos sucesos serios hasta una descarga aliviadora, otras veces debemos sentirnos elevados y entusiasmados con la victoria de los principios buenos y nobles, con el sacrificio del héroe en el sentido de una consideración moral del mundo; y con la misma certeza con que yo creo que para numerosos hombres es precisamente ese, y solo ese, el efecto de la tragedia, con esa misma claridad se infiere de aquí que todos ellos, junto con los estéticos que los interpretan, no han tenido ninguna experiencia de la tragedia como arte supremo ${ }^{65}$.

El efecto trágico no consiste ni en una descarga aliviadora ni en el triunfo moral de unos principios morales, sino en un estímulo y un tónico vital. Y así se recoge en el $\mathbb{} 5$ del capítulo titulado «Lo que debo a los antiguos» del Crepúsculo de los ídolos. Nietzsche se aleja allí tanto de Schopenhauer, el otro importante referente de su teoría de la tragedia y su crítica a la compasión, como de Aristóteles:

La psicología del orgiasmo entendido como un desbordante sentimiento de vida y de fuerza, dentro del cual el dolor mismo actúa como un estimulante, me dio la clave para entender el concepto de sentimiento trágico, sentimiento que ha sido malentendido tanto por Aristóteles como especialmente por nuestros pesimistas. La tragedia está tan lejos de ser una prueba del pesimismo de los helenos en el sentido de Schopenhauer, que ha de ser considerada, antes bien, como un rechazo y una contra-instancia decisivos de aquel. El decir sí a la vida incluso en sus problemas más extraños y duros; la voluntad de vida regocijándose de su propia inagotabilidad al sacrificar a sus tipos más altos, eso fue lo que yo adiviné como puente que lleva a la psicología del poeta trágico. No para desembarazase del espanto y la compasión, no para purificarse

62. Cf. ibid., pp. 200-202 (KSA 1, 520-522).

63. Véase ibid., pp. 203-205 (KSA 1, 523-525).

64. El nacimiento de la tragedia, cit., pp. 175-176 (KSA 1, 142).

65. Ibid. (La cursiva es nuestra). 
de un afecto peligroso mediante una vehemente descarga del mismo — así lo entendió Aristóteles-: sino para, más allá del espanto y la compasión, ser nosotros mismos el eterno placer del devenir —ese placer que incluye en sí también el placer de destruir... Y con esto vuelvo a tocar el sitio de que en otro tiempo partí - El nacimiento de la tragedia fue mi primera transvaloración de todos los valores: con esto vuelvo a situarme yo otra vez en el terreno del que brotan mi querer, mi poder -yo, el último discípulo del filósofo Dionisos, - yo, el maestro del eterno retorno... ${ }^{66}$.

Además de la distancia con respecto a Schopenhauer y Aristóteles, cabe destacar que Nietzsche interpreta la kátharsis aristotélica al modo de Bernays, a saber, como descarga aliviadora de una gran tensión, de tal manera que el placer estético de la tragedia radicaría, de acuerdo con la interpretación que Bernays hace de Aristóteles, en el alivio experimentado después de la descarga. En cambio, Nietzsche, con esta nueva concepción de lo trágico, se sitúa en la línea de una filosofía afirmativa que, pese a las diferencias de tono, tiene mucho en común con Spinoza, para quien el mundo como tal, como Natura naturans, no es susceptible de mejora en el sentido moral, porque es en sí perfecto, completo, necesario: «La perfección de las cosas debe estimarse por su sola naturaleza y potencia, y no son más o menos perfectas porque deleiten u ofendan los sentidos de los hombres, ni porque convengan o repugnen a la naturaleza humana ${ }^{67}$. Nietzsche podría sostener con Spinoza que la perfección está en el todo, que realidad es lo mismo que perfección ${ }^{68}$ y que necesidad. Como Spinoza, también Nietzsche sostiene que no hay nada superfluo en la naturaleza, ni nada imperfecto o censurable en ella; que los juicios morales no valen para el todo y que la naturaleza misma se sitúa «más allá del bien y del mal».

Pues bien, de acuerdo con esto, lo que aporta el punto de vista trágico no es una visión dramática de la existencia, sino un punto de vista estimulante: un tónico vital. Por eso, la emoción trágica por excelencia no puede ser la compasión ni tampoco el miedo, pues ambas tienen un efecto paralizante y depresivo. El $\$ 7$ de El Anticristo contiene una importante reflexión sobre esta temática en la que cabe destacar tres puntos. En primer lugar, Nietzsche considera la compasión como lo contrario de un tónico: es un sentimiento depresivo ${ }^{69}$. En segundo lugar, considera que solo una filosofía que niega la vida puede considerar la compasión como la virtud por excelencia ${ }^{70}$. Finalmente, Nietzsche advierte que en este punto no existe afinidad

66. Crepúsculo de los ídolos, «Lo que yo debo a los antiguos», trad. de A. Sánchez Pascual, Madrid: Alianza, 2009, pp. 143-144 (KSA 6, 160).

67. Ética I, Apéndice, trad. de V. Peña, Editora Nacional, Madrid, 1975, p. 103.

68. E II, def. VI, ed. cit., p. 109.

69. «Al cristianismo se lo llama religión de la compasión. La compasión es antitética de los afectos tonificantes, que elevan la energía del sentimiento vital: produce un efecto depresivo. Uno pierde fuerza cuando compadece. Con la compasión aumenta y se multiplica más aún la merma de fuerza que ya el padecer aporta en sí a la vida. El padecer (Leiden) mismo se vuelve contagioso mediante el compadecer (Mitleiden)» (El Anticristo, trad. de A. Sánchez Pascual, Madrid: Alianza, pp. 31-32 [KSA 6, 172-174]).

70. «Se ha osado llamar virtud a la compasión [...]; se ha ido más allá, se ha hecho de ella la virtud, el suelo y el origen de todas las virtudes, - pero solo, y esto hay que tenerlo siempre presente, desde el punto de vista de una filosofía que era nihilista, que inscribió en su escudo la negación de la vida. Schopenhauer estaba en su derecho al decir: mediante la compasión la vida queda negada, es hecha más digna de ser negada, - la compasión es la praxis del nihilismo» (ibid.). 
alguna entre Schopenhauer y Aristóteles y que este último está lejos de considerar la compasión como una emoción positiva. Nietzsche encuentra en la teoría aristotélica de la tragedia la postura de un médico que busca allí el efecto terapéutico de una descarga, de un alivio catártico. Es en esto, no en la valoración de la compasión, en lo que Nietzsche se aleja del filósofo griego: «Aristóteles, como se sabe, veía en la compasión un estado enfermizo y peligroso, al que se haría bien en tratar de vez en cuando con un purgativo: él concibió la tragedia como un purgativo» ${ }^{71}$.

En 1888, en la reflexión que ofrece Ecce Homo a propósito de El nacimiento de la tragedia, Nietzsche repite el párrafo del Crepúsculo referido más arriba. Esta vez, lejos ya del malentendido que le había llevado a considerar que Schopenhauer y Wagner serían los artífices de una nueva cultura trágica, se reconoce a sí mismo como el primer filósofo trágico, antítesis de un filósofo pesimista y el primero capaz de llevar a cabo una transposición de lo dionisíaco a un pathos filosófico ${ }^{72}$. Nietzsche augura allí un futuro dionisíaco de la música, un nuevo partido de la vida, a favor de la vida, y promete una «edad trágica»: «el arte supremo en el decir sí a la vida, la tragedia, volverá a nacer cuando la humanidad tenga detrás de sí la consciencia de las guerras más duras, pero más necesarias, sin sufrir por ello...» ${ }^{73}$.

Pero es quizá el fragmento póstumo fechado en la primavera de 1888, titulado "Qué es trágico», el que constituye la conclusión más clara e inequívoca de la posición nietzscheana respecto de Aristóteles y Schopenhauer ${ }^{74}$. Nietzsche insiste de nuevo en el efecto tónico y estimulante de la tragedia frente al efecto catártico defendido por Aristóteles o la resignación que Schopenhauer atribuía a las obras trágicas. Llega incluso a decir que, si se midiera el efecto de una emoción trágica con la ayuda de un dinamómetro, se podría comprobar que la tragedia es un tónico y eso ya bastaría para echar por tierra las dos posiciones señaladas: en un caso, el de Schopenhauer, porque considera que la tragedia produce resignación, es decir, una suave renuncia, una debilitación de los instintos y la convicción de que esta vida no merece nuestro apego. En el otro, el de Aristóteles, porque los dos afectos trágicos, el miedo y la compasión, son efectos deprimentes y es falso que la exaltación de los mismos sea el camino para liberarse de ellos. Ni resignación ni kátharsis: la tragedia es una forma del arte, quizás la más elevada, pero, en todo caso, y como todo arte es «el gran estimulante de la vida, una ebriedad en el vivir, una voluntad de vida» ${ }^{75}$.

71. Ibid.

72. «En este sentido tengo derecho a considerarme el primer filósofo trágico — es decir, la máxima antítesis y el máximo antípoda de un filósofo pesimista. Antes de mí no existía esta transposición de lo dionisíaco a un pathos filosófico: falta la sabiduría trágica, - en vano he buscado indicios de ella incluso en los grandes griegos de la filosofía, la de los dos siglos anteriores a Sócrates. Me ha quedado una duda con respecto a Heráclito, en cuya cercanía siento más calor y me encuentro de mejor humor que en ningún otro lugar. La afirmación del fluir y del aniquilar, que es lo decisivo en la filosofía dionisíaca, el decir sí a la antítesis y a la guerra, el devenir, el rechazo radical incluso del mismo concepto 'ser' - en esto tengo que reconocer, bajo cualquier circunstancia, lo más afín a mí entre lo que hasta ahora se ha pensado» (Ecce Homo, trad. de A. Sánchez Pascual, Madrid: Alianza, 1984, pp. 70-71 [KSA 6, 312-313]).

73. Ibid., p. 71 (KSA 6, 313).

74. Fragmento 15 [10]. Primavera de 1888: «Qué es trágico», en Fragmentos Póstumos (18851889), vol. IV, trad., introd. y notas de J. L. Vermal y J. B. Llinares, Tecnos, Madrid, 2006, pp. 626627 (KSA 13, 409-411).

75. Ibid. 